\title{
Tabakalı Hibrit Kompozitlerin Bireysel Zırh Malzemesi Olarak Üretimi Ve Balistik Performanslarının İncelenmesi
}

\author{
Cenk YANEN* Murat Yavuz SOLMAZ* \\ Fırat Üniversitesi, Mühendislik Fakültesi, Makine Mühendisliği Bölümü, 23119 Elazı̆̆/TÜRKIYE \\ cyanen@firat.edu.tr
}

Geliş/Received: 10.11 .2015

Düzeltme/Revised: -

Kabul/Accepted: 10.12 .2015

Özet: Bu çalışmada, tabakalı hibrit kompozitlerin bireysel zırh malzemesi olarak kullanılabilirliği deneysel olarak araştırılmışıı. Çalışma kapsamında farklı fiber takviye açılarına, farklı tabaka sayılarına ve farklı kalınlıklara sahip Cam Fiber/Aramid Fiber/Karbon Fiber tabakalı kompozit plakaların balistik deneyleri yapılmış ve sonuçları incelenmiştir. Bu amaçla 200x200mm boyutlarındaki 30 tabakalı farklı kalınlıkta 4 adet plaka elle yatırma yöntemi kullanılarak üretilmiştir. Farklı fiber takviye açılarının balistik performansının incelenebilmesi için $0^{\circ}, 45^{\circ}$, plain ve twill kumaşlar kullanılmıştır. Üretimi yapılan tabakalı hibrit kompozit plakaların balistik testleri Elazı̆̆ Özel Harekât Şube Müdürlüğü atış poligonlarında Beretta marka tabanca ile 9mm FMJ mermi kullanılarak yapılmıştır.

Anahtar kelimeler: Hibrit kompozit, Balistik performans, Zırh malzemesi.

\section{Production of Laminated Hybrid Composites As A Body Armor Material And Investigation of Ballistic Performance}

\begin{abstract}
In this study, usability of laminated hybrid composites as a body armor material has been investigated experimentally. As part of the study, ballistic tests of glass/aramid/carbon fiber laminated composite plates with different reinforcing angles, in different numbers and thicknesses have been carried out and the results are analyzed. To this end, 4 plates, each having different thicknesses and comprising 30 laminates in 200x200mm size are produced by hand lay-up method. $0^{\circ}, 45^{\circ}$, plain and twill fabrics have been used to analyze ballistic performances of different fiber reinforcing angles. Ballistic tests of the laminated hybrid composite plates that are produced are carried out in Elazığ Special Operation Branch Office, using a Beretta gun loaded with $9 \mathrm{~mm}$ FMJ bullets.
\end{abstract}

Keywords: Hybrid composite, Ballistic performance, Armor material

\section{Giriş}

İnsan, hayatta kalma içgüdüsüyle tarih boyunca her zaman kendini koruma ihtiyacı içinde olmuştur. Gerek günlük hayatta gerekse savaş alanlarında olsun insanoğlu bu içgüdüyle sürekli çalışmıştır. Kendini savunmak için taş ve sopaların kullanımı ile başlayan silahları geliştirmiştir. Silahlanmanın genişlemesiyle birlikte de savunma için koruyucu zırh ve kalkan kullanılmaya başlanmıştır. Savaşlar geçirmiş ve bu savaşlarda ürettiği silah ve zırh teknolojisini kullanmıştır. 13. yüzyılda

Bu makaleye atıf yapmak için

Yanen, C., Solmaz, M.Y., "Tabakalı Hibrit Kompozitlerin Bireysel Zırh Malzemesi Olarak Üretimi Ve Balistik Performanslarının İncelenmesi” El-Cezerî Fen ve Mühend is lik Dergisi 2016, 3(2); 351-362. 
kılıçla savaşan ya da kendisini koruyan insanoğlu yine bu dönemde tüm vücudunu saran çelik elbiseleri tehlikelere karşı kalkan olarak kullanmıştır. [1]

Hızla gelişen silah teknolojisi barutun ve ateşli silahların icadıyla yeni bir boyut kazanmıştır. Silahların ağırlığı azalıp boyutları küçülürken etki ve menzilleri artmıştır. Buna paralel olarak gerek bina ve araç gerekse personel zırhında yüksek başarım ve düşük yoğunluk ihtiyacı kaçınılmaz olmuştur. Tüm tarihsel gelişme boyunca hafif ve esnek malzemeler araştırılarak, daha hafif vücut zırh sistemleri ile mobiliteyi artırmak ve aynı zamanda belirli tehditlere karşı koruma sağlanması hedeflenmiştir. Bunun bir sonucu olarak, gelişmiş hafif vücut zırhı malzemelerinin gelişmesine neden olmuştur. [2]

Kompozit malzemeler, iki veya daha fazla malzemenin bir araya getirilmesiyle yeni bir malzemenin meydana getirilmesi olarak tanımlanabilir. Burada amaç, kullanılan malzemelerin birbirlerinin zayıf kalan yönlerini iyileştirmek ve istenilen yönde daha üstün özellik sağlayan bir malzeme elde etmektir.

Tan vd., tek katmanlı Twaron kumaşının balistik performansı üzerine yaptıkları deneysel çalışmalarında, farklı kalibredeki mermilerle, karşılıklı iki kenarlarından sıkıştırılmış dikdörtgen kumaş numuneleri üzerinde çarpma testleri yapmışlardır. Çalışmalar neticesinde, gelişmekte olan mermi tipleri ile kumaş arasındaki sürtünmenin, çarpma sırasındaki enerjinin sönümlenmesinde önemli bir mekanizma olduğu görülmektedir. [3]

Karahan vd., farklı kat adedinden oluşan koruyucu zırh kumaşlarının balistik performansı ile ilgili araştırma sonuçlarını incelemiştir. Twaron CT 170 tip kumaş katmanları farklı sayılarda ve farklı dikiş tipleri ile birleştirilmiş ve panel oluşturulmuş, bu paneller NIJ standartlarına göre yapılan balistik testlerden geçirilmiş, balistik performansı, atış sonrası koruyucu panel arkasında oluşan çöküntü derinliği ve çöküntü çapının ölçülmesi ile belirlenmiştir. Bu testler tabaka kalınlığı ile dikiş tiplerinin balistik performans üzerinde önemli bir etkiye sahip olduğunu, dikişin daha yoğun kullanıldığı yapılardaki çöküntü miktarlarında diğerlerine göre \% 6,7 oranında azalma olduğunu göstermiştir. [4]

Bilişik ve Turhan, tarafindan yapılan çalışmada Kevlar 29 elyaf dokuma ile tek fazlı ve Kevlar 29 ile Kevlar 129 elyaf dokumalarla iki fazlı olarak oluşturdukları toplam 4 çeşide ait dikişsiz ve dikişli kompozit numuneler üretilmiştir. Bu kompozit numunelerin 5 farklı mermi cinsine karş1 balistik performansını araştııılmıştır. Yaptıkları çalışmada absorbe edilen enerji yönünden dikişli ve dikişsiz numuneler arasında belirgin bir fark bulunmadığı, ancak çöküntü miktarının dikişli yapılarda daha fazla olduğu sonucuna ulaşılmıştır. [5]

Yu vd., tarafindan yapılan çalışmada takviye elemanı olarak 3 boyutlu ortagonal dokuma Kevlar 29 ile yine aynı yapıda E-cam kullanarak vinylester reçine matrisle numuneler hazırlanmıştır. Bu numuneler ile yapılan deneysel çalışmalarda numunelere $5 \mathrm{~mm}$ çapında çelik küre ile $600 \mathrm{~m} / \mathrm{sn}$ ile $1050 \mathrm{~m} / \mathrm{sn}$ arasındaki hızlarda atışlar yaparak numunelerin balistik özellikleri araştırılmıştır. Çalışmalarda çelik kürenin kinetik enerjisinin büyük miktarını her iki numune cinsinde de $Z$ eksenindeki fiberlerin absorbe ettiğini, Kevlar 29 takviyeli numunelerin daha fazla enerji absorbe edebildikleri gözlemlenmiştir. [6]

$\mathrm{Bu}$ çalışmada savunmada kullanılan bireysel koruyucu zırhların, hibrit kompozit plakalar kullanılarak geliştirilmesi amaçlanmıştır. Çalışmalar neticesinde kişisel koruyucu zırhların, daha hafif ve koruma özelliği yüksek olması için yapılacak uygulamalara deneysel altyapı sağlanmış ve yeni hazırlanacak zırh kombinasyonları için farklı fikirler ortaya konulması sağlanmıştır. 


\section{Deneysel Çalışmalar}

Bu çalışma kapsamında yapılan deneysel çalışmada kullanılan 4 adet tabakalı hibrit kompozit plaka Fırat Üniversitesi Mühendislik Fakültesi Makine Mühendisliği Mekanik Laboratuvarında üretilmiştir. Tabakalı hibrit kompozit plaka numunelerinin üretimi için elle yatırma yöntemi kullanılmıştır.

Tabakalı hibrit kompozitlerin üretiminde matriks malzemesi olarak balistik dayanımı artırmak amacıyla yüksek sıcaklığa dayanıklı polyester reçine ve sertleştirici kullanılmıştır. Takviye malzemesi olarak da 4 farklı karbon elyaf, 4 farklı cam elyaf ve Kevlar 49 Aramid elyafi kullanılmıştır Deneylerde kullanılan takviye malzemelerinin özellikleri Tablo 1. de verilmiştir.

Tablo 1. Deneyde kullanılan takviye malzemeleri

\begin{tabular}{|l|l|l|l|}
\hline Sıra & Malzeme Adı & Türü & Kütlesi \\
\hline 1 & Karbon Elyaf & Dikişli $0^{\circ}$ & $300 \mathrm{gr} / \mathrm{m}^{2}$ \\
\hline 2 & Karbon Elyaf & Dikişli 45 & $400 \mathrm{gr} / \mathrm{m}^{2}$ \\
\hline 3 & Karbon Elyaf & Dokuma Plain & $200 \mathrm{gr} / \mathrm{m}^{2}$ \\
\hline 4 & Karbon Elyaf & Dokuma Twill & $245 \mathrm{gr} / \mathrm{m}^{2}$ \\
\hline 5 & Cam Elyaf & Dikişli $0^{\circ}$ & $300 \mathrm{gr} / \mathrm{m}^{2}$ \\
\hline 6 & Cam Elyaf & Dikişli $45^{\circ}$ & $460 \mathrm{gr} / \mathrm{m}^{2}$ \\
\hline 7 & Cam Elyaf & Dokuma Plain & $200 \mathrm{gr} / \mathrm{m}^{2}$ \\
\hline 8 & Cam Elyaf & Dokuma Twill & $282 \mathrm{gr} / \mathrm{m}^{2}$ \\
\hline 9 & Kevlar 49 Aramid Elyaf & Dokuma Plain & $410 \mathrm{gr} / \mathrm{m}^{2}$ \\
\hline
\end{tabular}

$\mathrm{Bu}$ çalışmada kullanılan tabakalı hibrit kompozit numunelerin üretimi için elle yatırma yöntemi seçilmiştir. Elle yatırma yönteminde şu şekilde gerçekleştirilmiştir. Üretime başlamadan önce kumaşlar (200x200) mm ölçülerinde Radwag marka elektrikli makas kullanılarak kesilmiştir. Kesilen kumaşlar hassas terazi kullanılarak tartılmıştır. Daha sonra alt ve üst kalıp raspa ve zımpara yardımıyla temizlenmiş ve bir fırça yardımıyla kalıp ayırıcı sürülmüş ve kuruması için beklemeye alınmıştır. Ardından MGS L326 marka polyester reçine ve H265 marka sertleştirici, 4 birim reçine için 1 birim sertleştirici olacak şekilde karışım oranları ayarlanarak hazırlanmıştır. Alt kalıba bir miktar polyester reçine ve sertleştirici karışımı dökülerek rulo yardımıyla kalıba yayılmıştır. Kalıp içerisine $(200 \times 200) \mathrm{mm}$ ölçülerinde kesilen kumaşlardan numune düzenine göre seçilen ilk kat serilerek üzerine polyester karışım dökülmüş ve rulo yardımıyla kumaşa eşit bir şekilde dağılması sağlanmıştır. Bir kat daha kumaş serilerek yeniden polyester karışım dökülmüş ve kumaşın polyesterle iyice ıslanması ve hava boşluklarının uzaklaştırılabilmesi için rulo yardımıyla yayılmıştır. Tüm kumaşlar için bu işlemler tekrarlanmıştır. Bütün kumaşlar serildikten ve polyester karışımı en üstede sürüldükten sonra üst kalıp kapatılmıştır. Son olarak kalıp hidrolik prese koyulmuş ve 30 bar basınçta preslenmiştir. Presleme işlemi sırasında numune $20 \mathrm{C}^{\circ}$ de başlayıp $110 \mathrm{C}^{\circ}$ ye kadar kademeli olarak artırılarak 4 saatte kürleme işlemi yapılmıştır. Balistik testlerde kullanılacak tabakalı hibrit kompozitlere ait yapı şeması Şekil 1. de verilmiştir. Balistik testlerin tamamı önde cam elyaf, ortada aramid elyaf ve arkada karbon elyaf olacak şekilde gerçekleştirilmiştir. 


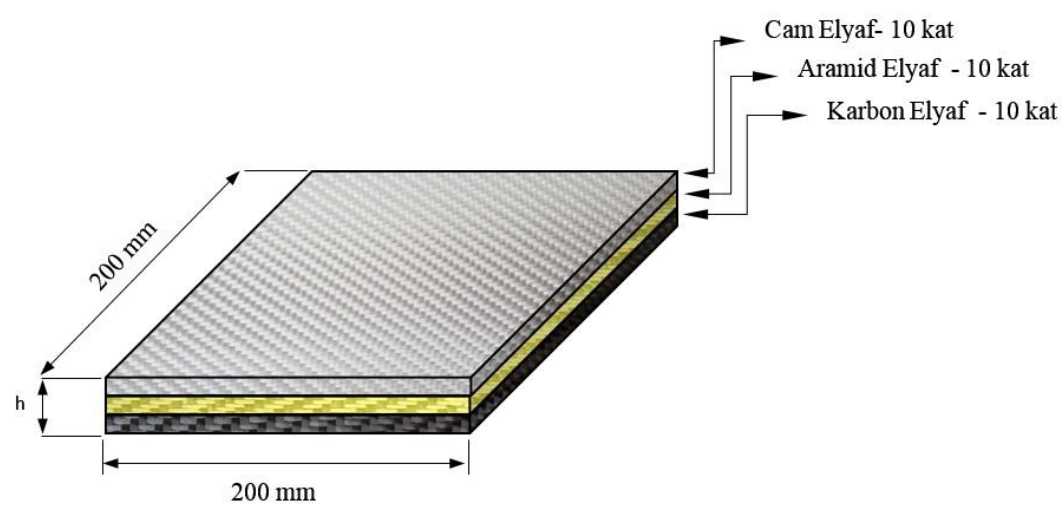

Şekil 1. $\left[\mathrm{Cam}_{10} / \mathrm{Aramid}_{10} / \mathrm{Karbon}_{10}\right] 30$ tabakalı hibrit polyester reçine matriksli numunelerin yap1 şemas1

Üretim sonrası elde edilen numunelere ait fotoğraflar Şekil 2. de verilmiştir.

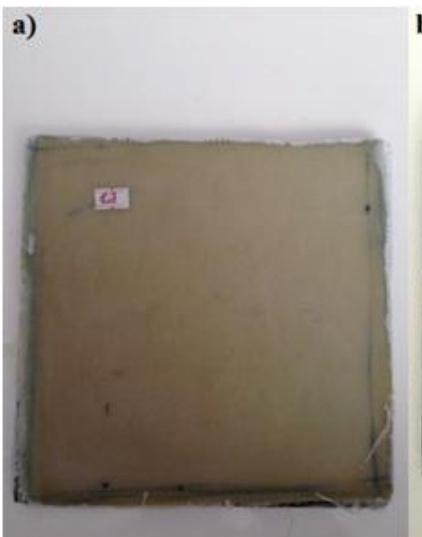

b)

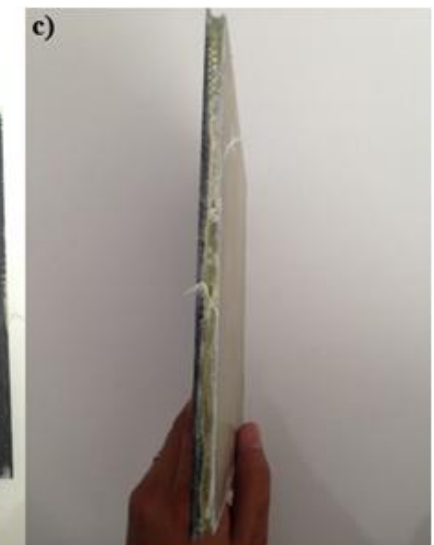

Şekil 2. $\left[\mathrm{Cam}_{10} / \mathrm{Aramid}_{10} / \mathrm{Karbon}_{10}\right] 30$ tabakalı hibrit polyester reçine matriksli numuneler a) ön görünüş b) arka görünüş c) kesit görünüş

$\mathrm{Bu}$ çalışma kapsamında üretilen 4 adet tabakalı hibrit kompozitin konfigürasyonu Tablo 2. de verilmiştir.

Tablo 2. Kompozit Numunelerin Konfigürasyonu

\begin{tabular}{|c|c|c|c|c|c|c|}
\hline \multicolumn{7}{|c|}{ Numune Özellikleri } \\
\hline $\begin{array}{l}\text { Numune } \\
\text { Adı }\end{array}$ & Malzeme & $\begin{array}{l}\text { Kat } \\
\text { Sayısı }\end{array}$ & $\begin{array}{l}\text { Boyut } \\
\text { (mm) }\end{array}$ & $\begin{array}{l}\text { A ğırlık } \\
\text { (gr) }\end{array}$ & $\begin{array}{l}\text { Kalınlık } \\
(\mathbf{m m})\end{array}$ & $\begin{array}{l}\text { Üretim } \\
\text { Sonrası } \\
\text { Ağırlık (gr) }\end{array}$ \\
\hline \multirow{3}{*}{ B1 } & Karbon Fiber $45^{\circ}(400 \mathrm{gr} / \mathrm{m} 2)$ & 10 & $200 * 200$ & 172.94 & \multirow{3}{*}{13} & \multirow{3}{*}{818} \\
\hline & Aramid Fiber Plain $(410 \mathrm{gr} / \mathrm{m} 2)$ & 10 & $200 * 200$ & 155.29 & & \\
\hline & Cam Fiber $45^{\circ}(460 \mathrm{gr} / \mathrm{m} 2)$ & 10 & $200 * 200$ & 197.82 & & \\
\hline \multirow{3}{*}{ B2 } & Karbon Fiber $0^{\circ}(300 \mathrm{gr} / \mathrm{m} 2)$ & 10 & $200 * 200$ & 125.87 & \multirow{3}{*}{11} & \multirow{3}{*}{656} \\
\hline & Aramid Fiber Plain $(410 \mathrm{gr} / \mathrm{m} 2)$ & 10 & $200 * 200$ & 166.60 & & \\
\hline & Cam Fiber $0^{\circ}(300 \mathrm{gr} / \mathrm{m} 2)$ & 10 & $200 * 200$ & 125.30 & & \\
\hline \multirow{3}{*}{ B3 } & Karbon Fiber Plain (200gr/m2) & 10 & $200 * 200$ & 79.13 & \multirow{3}{*}{9} & \multirow{3}{*}{550} \\
\hline & Aramid Fiber Plain $(410 \mathrm{gr} / \mathrm{m} 2)$ & 10 & $200 * 200$ & 160.91 & & \\
\hline & Cam Fiber Plain (200gr/m2) & 10 & $200 * 200$ & 81,16 & & \\
\hline \multirow{3}{*}{ B4 } & Karbon Fiber Twill $(245 \mathrm{gr} / \mathrm{m} 2)$ & 10 & $200 * 200$ & 81.63 & \multirow{3}{*}{9.5} & \multirow{3}{*}{598} \\
\hline & Aramid Fiber Plain $(410 \mathrm{gr} / \mathrm{m} 2)$ & 10 & $200 * 200$ & 160.73 & & \\
\hline & Cam Fiber Twill (282gr/m2) & 10 & $200 * 200$ & 98.45 & & \\
\hline
\end{tabular}


Balistik testler bazı standartlar göz önüne alınarak yapılmaktadır. Bu çalışmada kapsamında yapılan deneysel çalışmada kompozit numunelerin balistik performansının ölçümünde National Institute of Justice (NIJ) değerleri referans olarak alınmıştır. NIJ0101.06 standardında kullanılan merminin kalibresi, tipi, ağırlığı ve hızı dikkate alınarak çeşitli koruma seviyeleri tanımlanmıştır. Tablo 3. de NIJ standartları verilmiştir. [7]

Tablo 3. NIJ 0101.06 Standart1

\begin{tabular}{|c|c|c|c|}
\hline Koruma Seviyesi & Mermi Tipi & Atış Hızı (m/sn) & $\begin{array}{l}\text { Çekirdek } \\
\text { Ăğırlığı (gr) }\end{array}$ \\
\hline $\begin{array}{l}\text { Seviye II-A } \\
\text { (5m mesafeden) }\end{array}$ & $\begin{array}{l}\text { 9mm FMJ } \\
40 \mathrm{~S} \& W \text { FMJ }\end{array}$ & $\begin{array}{l}373 \pm 9.1 \\
352 \pm 9.1\end{array}$ & $\begin{array}{l}8 \\
11.7\end{array}$ \\
\hline $\begin{array}{l}\text { Seviye II } \\
(5 \mathrm{~m} \text { mesafeden })\end{array}$ & $\begin{array}{l}357 \text { Mag. JSP } \\
\text { 9mm FMJ }\end{array}$ & $\begin{array}{l}436 \pm 9.1 \\
398 \pm 9.1\end{array}$ & $\begin{array}{l}10.2 \\
8.0\end{array}$ \\
\hline $\begin{array}{l}\text { Seviye III-A } \\
(5 \mathrm{~m} \text { mesafeden })\end{array}$ & $\begin{array}{l}\text { 0.44 Mag, JHP } \\
\text { 9mm FMJ RN }\end{array}$ & $\begin{array}{l}436 \pm 9.1 \\
448 \pm 9.1\end{array}$ & $\begin{array}{l}15.6 \\
8.1\end{array}$ \\
\hline $\begin{array}{l}\text { Seviye III } \\
(15 \mathrm{~m} \text { mesafeden })\end{array}$ & $7.62 \mathrm{~mm}$ NATO FMJ & $838 \pm 9.1$ & 9.6 \\
\hline $\begin{array}{l}\text { Seviye IV } \\
\text { (15m mesafeden) }\end{array}$ & 30 kalibre M2 AP & $878 \pm 9.1$ & 10.8 \\
\hline
\end{tabular}

Hafif silahlara karşı kullanılan zırhlar için balistik performansın ölçümünde iki ana tehdit göz önünde tutulmaktadır. Bunlardan birincisi parça tesirine karşı koruma, diğeri ise mermi tesirine karşı korumadır. Mermiye karşı korumada NIJ 0101.06 standart değerleri referans olarak alınmıştır. $\mathrm{Bu}$ kapsamda atış test sisteminin şeması Şekil 3. de verilmiştir. Test düzeneğinde bulunan Chrony F1 Master marka kronograf ile merminin hızı tespit edilmektedir. Testler sırasında atışlar bir kişi tarafından yapılarak bütün numuneler için aynı şartlarda atış yapılması sağlanmıştır.

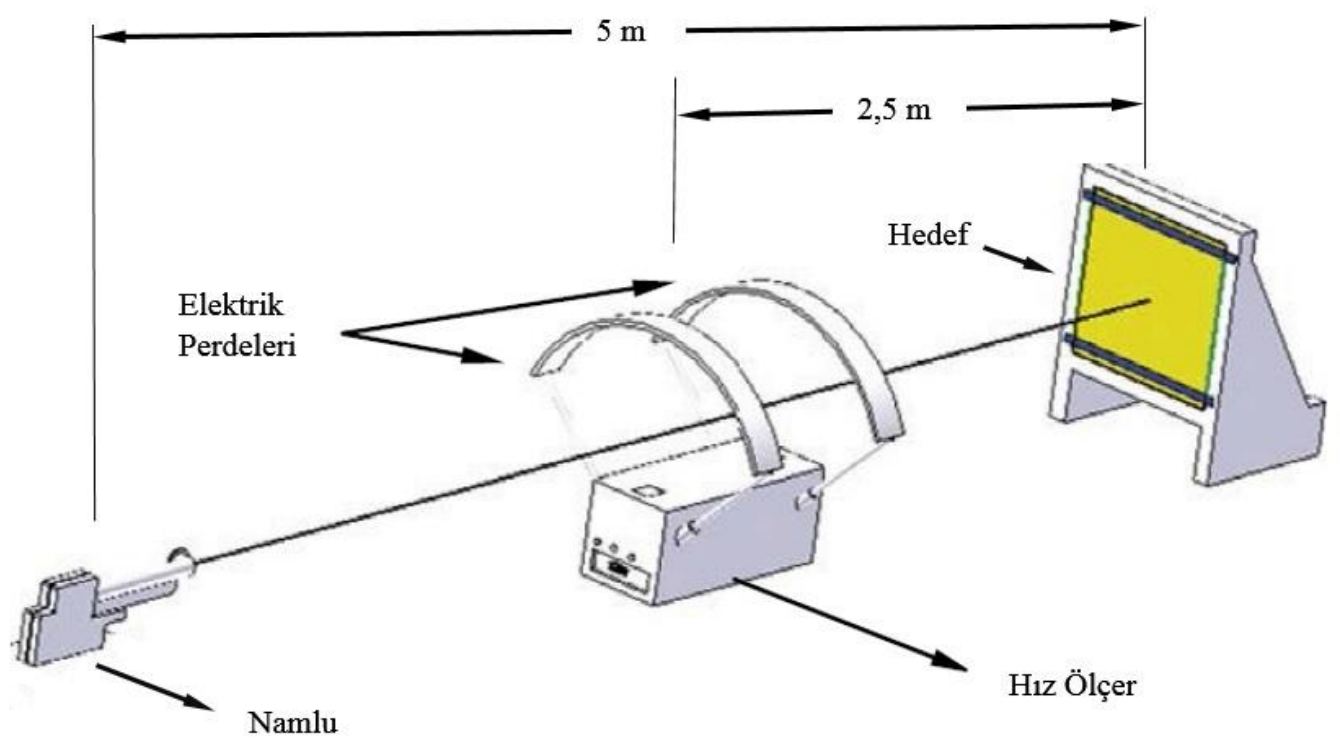

Şekil 3. Balistik test düzeneğinin şematik gösterimi

Deneyler sırasında tabanca atışları NIJ 0101.06 standardında belirtildiği gibi $5 \mathrm{~m}$ mesafeden yapılmıştır. Kronograf NIJ 0101.06 standardında belirtildiği gibi hedef ile tabanca arasında hedeften 2,5 m mesafede olacak şekilde konumlandırılmıştır. Bu atışlar neticesinde farklı hızlarda meydana gelen deformasyon oluşan çöküntü miktarlarıyla ölçülmüştür. Deney düzeneği Şekil 4. de verilmiştir. 


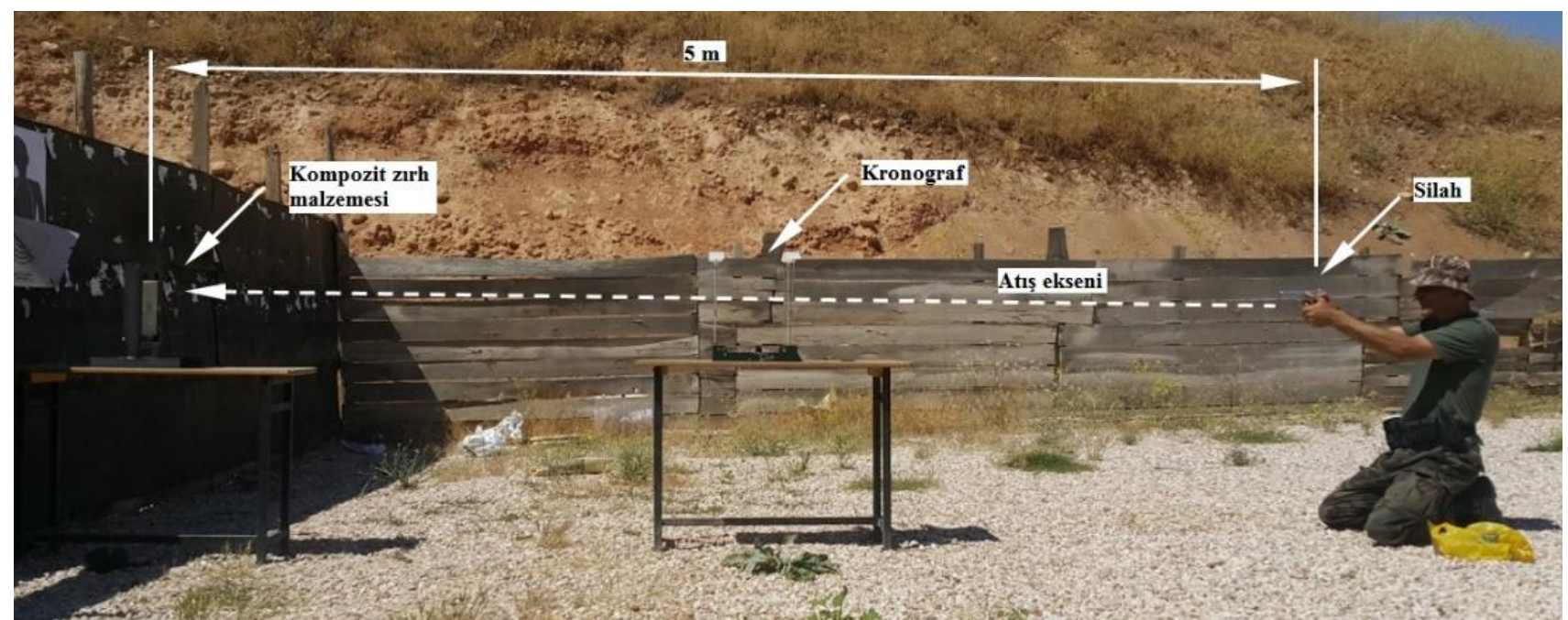

Şekil 4. Deney düzeneği

Farklı amaçlara hizmet eden birçok mermi türü değişik silahlar ile gelişen teknolojiyle beraber hız, şekil, çekirdek yapısı gibi özellikleri birbirinden çok farklı, değişik amaçlar için üretilmiştir. Bu çalışma kapsamında yapılan balistik testlerde $9 \mathrm{~mm}$ pirinç gövdeli, bakır kaplamalı mermi kullanılmıştır. Kullanılan $9 \mathrm{~mm}$ merminin teknik özellikleri Tablo 4. de, yapı resmi ve çekirdek ölçüleri Şekil 5. de verilmiştir.

Kinetik enerjiye sahip bir merminin hedef üzerindeki delici etkisi, merminin kütlesine, enerjisine, hedefe vuruş açısına ve mermi ile zırh malzemesinin metalurjik yapısına bağlıdır. Merminin kütlesi (m) ve çarpma anındaki hız $\left(\mathrm{V}_{\mathrm{m}}\right)$ olduğunda merminin kinetik enerjisi;

$E_{k}=\frac{1}{2} m V_{m}^{2}$

şeklindedir. [8]

Tablo $4.9 \mathrm{~mm}$ standart mermi özellikleri

\begin{tabular}{ll} 
Çekirdek çapı $(\mathrm{mm})$ & 9,08 \\
Çekirdek ağırlı̆̆ı $(\mathrm{gr})$ & 8 \\
Kovan ağırlı̆̆ı $(\mathrm{gr})$ & 3,80 \\
Çekirdek uzunluğu (mm) & 15,70 \\
Standart barut miktarı (gr) & $0,41 \pm 0,005$ \\
\hline
\end{tabular}

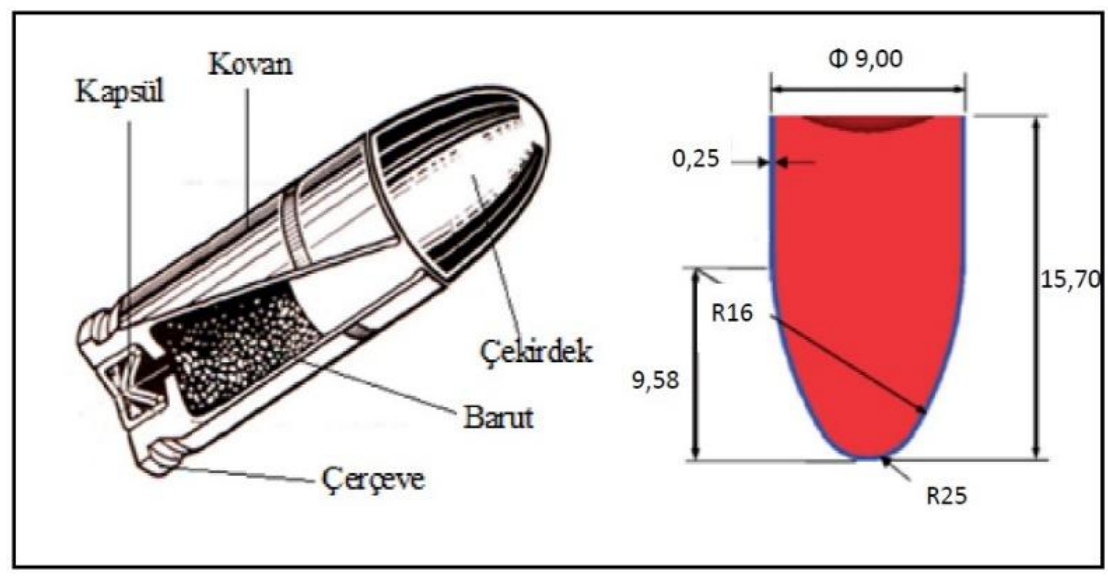

Şekil 5. 9mm mermi [9] 


\section{Deney Sonuçlarının Değerlendirilmesi}

$\mathrm{Bu}$ çalışma kapsamında üretimi yapılan tabakalı hibrit kompozit numunelerin balistik testleri NIJ standartlarına uygun olarak Elazığ Özel Harekât Şube Müdürlügünde yapılmıştır. Balistik testler sırasında atışlar Beretta marka tabanca kullanılarak bir personel tarafindan yapılmıştır. Atış sonrası balistik test numunelerine ait fotoğraflar aşağıda verilmiştir.

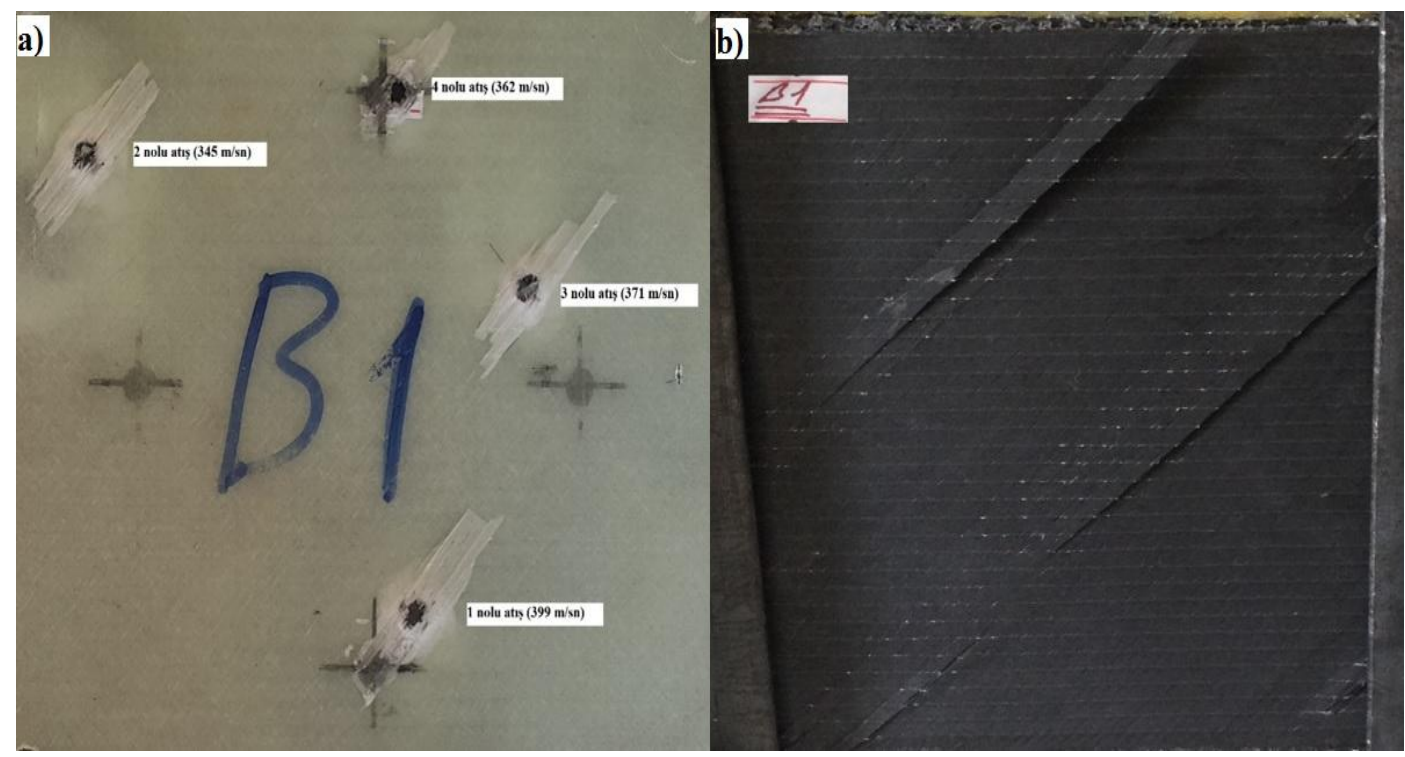

Şekil 6. $\left[\mathrm{Cam}\left(45^{\circ}\right)_{10} / \operatorname{Aramid}(\operatorname{Plain})_{10} / \operatorname{Karbon}\left(45^{\circ}\right)_{10}\right]$ numunesinin balistik test sonucu fotoğrafı a) ön görünüş b) arka görünüş

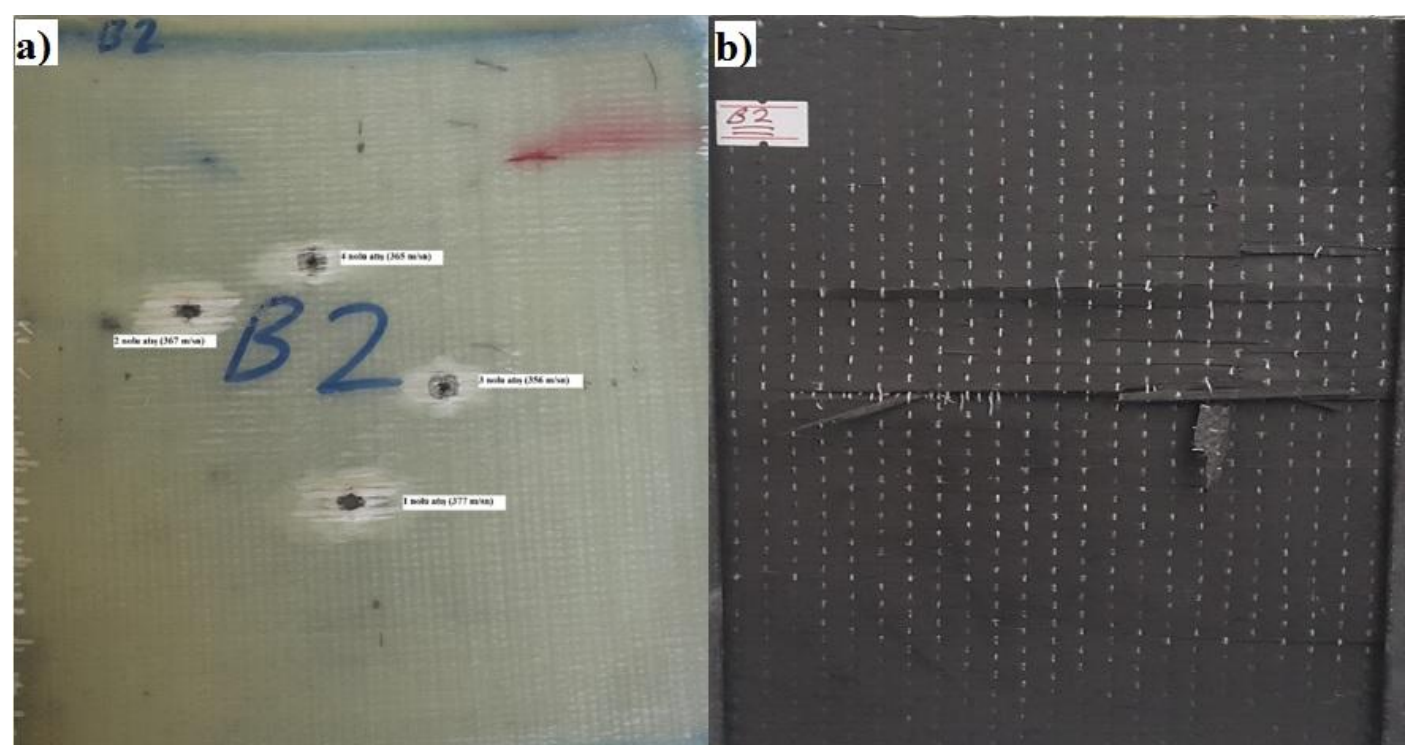

Şekil 7. $\left[\operatorname{Cam}\left(0^{\circ}\right)_{10} / \operatorname{Aramid}(\operatorname{Plain})_{10} / \operatorname{Karbon}\left(0^{\circ}\right)_{10}\right]$ numunesinin balistik test sonucu fotoğrafi a) ön görünüş b) arka görünüş 


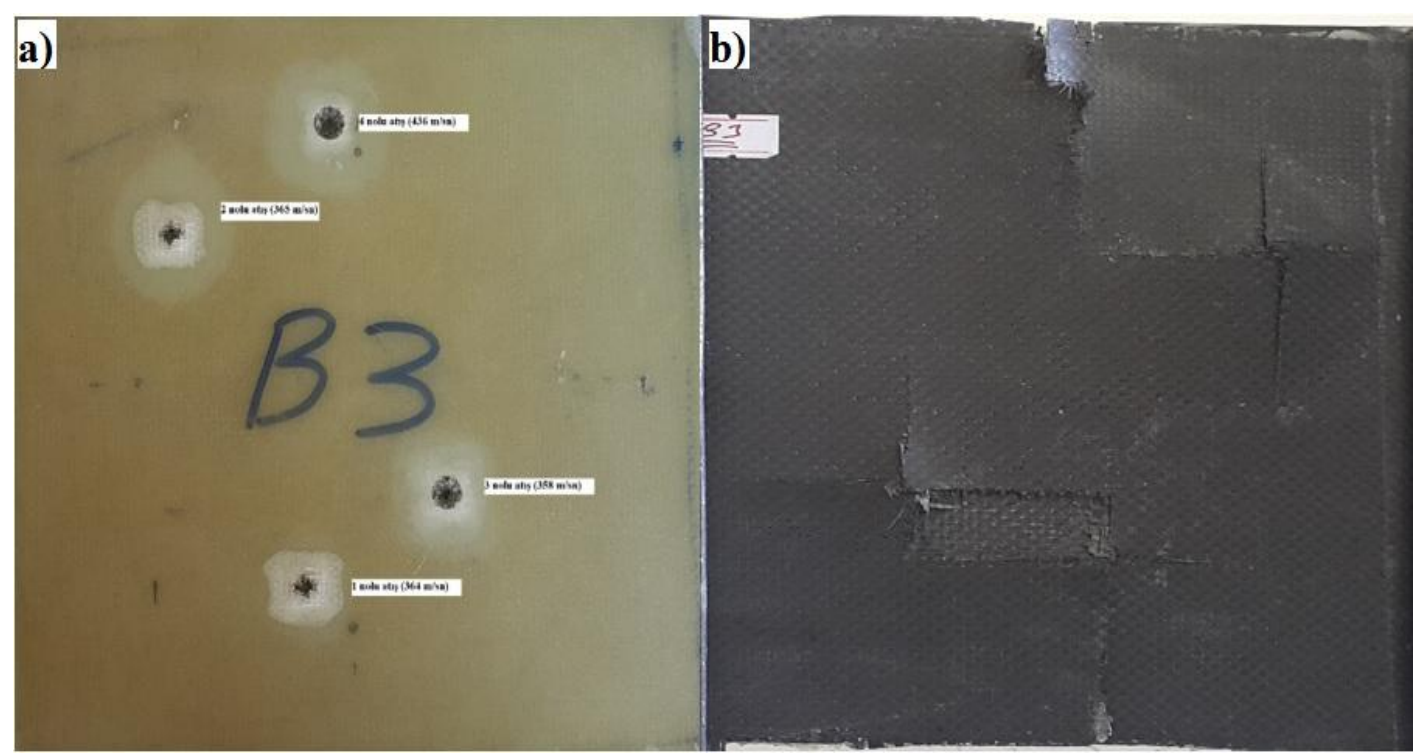

Şekil 8. [Cam(Plain) ${ }_{10} /$ Aramid(Plain) ${ }_{10} /$ Karbon(Plain) $\left.{ }_{10}\right]$ numunesinin balistik test sonucu fotoğrafi a) ön görünüş b) arka görünüş

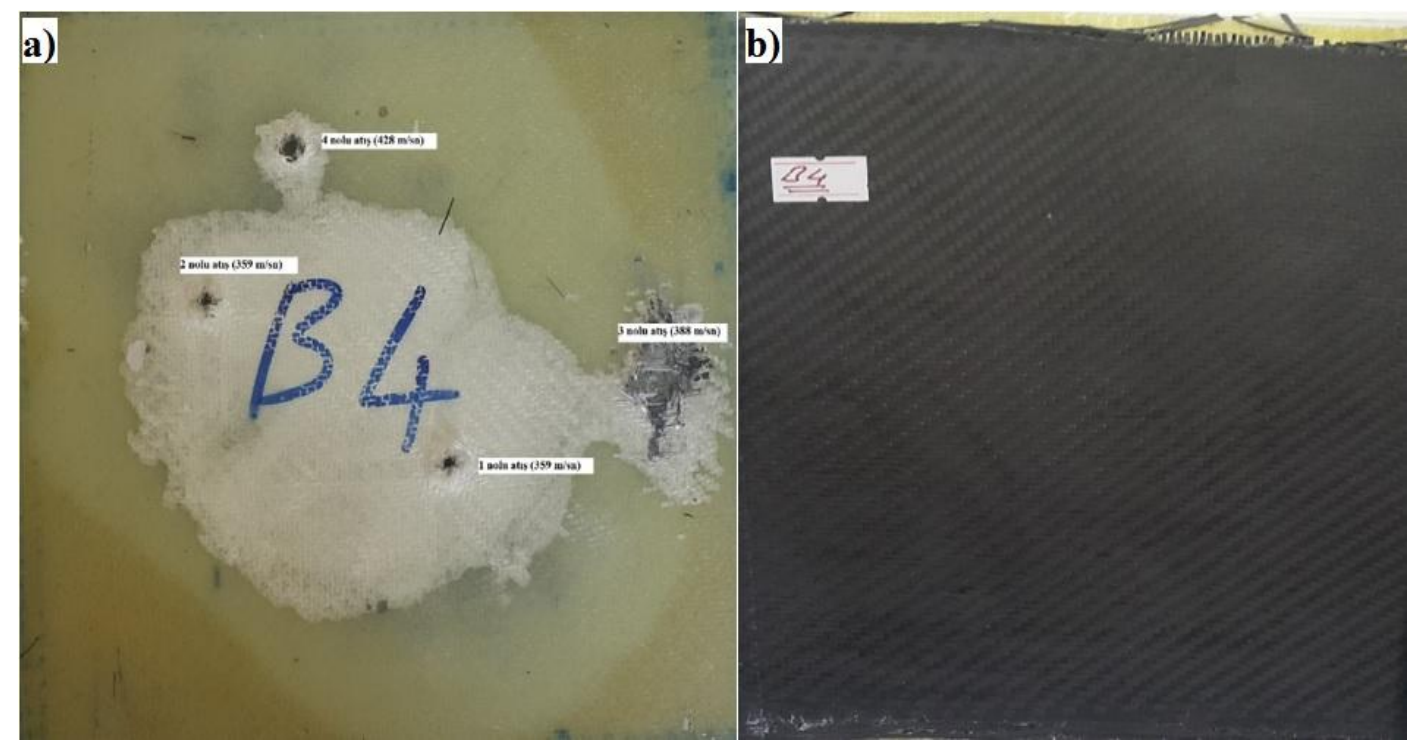

Şekil 9. [Cam(Twill) ${ }_{10} /$ Aramid(Plain) $\left.{ }_{10} / \operatorname{Karbon}(T \text { will })_{10}\right]$ numunesinin balistik test sonucu fotoğrafi a) ön görünüş b) arka görünüş

Zırh malzemesine giren merminin oluşturduğu arka yüz izi karşılaştırmalarında NIJ standardı 44 mm'ye kadar izin vermektedir. Bu ölçü daha fazla olduğu takdirde darbe travması etkisi yapıp yaralanmaya ve ölümlere neden olabilecektir. [10] Tabakalı hibrit kompozit numunelerin balistik testleri neticesinde elde edilen sonuçlar Tablo 5. de verilmiştir.

Tablo 5. Balistik test sonuçları

\begin{tabular}{lllll}
\hline \multicolumn{2}{l}{ Numune Adı: B1 } & & & \\
\hline Atış No & Atış Hızı (m/sn) & Kinetik Enerji (Nm) & Çöküntü Miktarı (mm) & Değerlendirme \\
\hline 1 & 399 & 635,78 & 6,20 & Delinme Yok \\
2 & 345 & 476,19 & 4,50 & Delinme Yok \\
3 & 371 & 551,30 & 5,90 & Delinme Yok \\
4 & 362 & 523,59 & 5,50 & Delinme Yok \\
Ortalama & $\mathbf{3 6 9}$ & $\mathbf{5 4 6 , 7 1}$ & $\mathbf{5 , 5 3}$ & \\
& & & & \\
\hline
\end{tabular}




\begin{tabular}{|c|c|c|c|c|}
\hline \multicolumn{5}{|c|}{ Numune Adı: B2 } \\
\hline Atış No & $\operatorname{Atış~Hızı~(m/sn)~}$ & Kinetik Enerji (Nm) & Çöküntü Miktarı (mm) & Değerlendirme \\
\hline 1 & 377 & 569,55 & 8,45 & Delinme Yok \\
\hline 2 & 367 & 539,59 & 7,40 & Delinme Yok \\
\hline 3 & 356 & 507,83 & 5,00 & Delinme Yok \\
\hline 4 & 365 & 533,34 & 6,00 & Delinme Yok \\
\hline Ortalama & 367 & $\mathbf{5 3 7 , 5 8}$ & 6,71 & \\
\hline \multicolumn{5}{|c|}{ Numune Adı: B3 } \\
\hline Atış No & Atış Hızı (m/sn) & Kinetik Enerji (Nm) & Çöküntü Miktarı (mm) & Değerlendirme \\
\hline 1 & 364 & 529,78 & 7,20 & Delinme Yok \\
\hline 2 & 365 & 533,34 & 8,50 & Delinme Yok \\
\hline 3 & 358 & 512,18 & 7,00 & Delinme Yok \\
\hline 4 & 436 & 760,97 & 9,00 & Delinme Yok \\
\hline Ortalama & 381 & 584,07 & 7,93 & \\
\hline \multicolumn{5}{|c|}{ Numune Adı: B4 } \\
\hline Atış No & $\operatorname{Atış~Hızı~(m/sn)~}$ & Kinetik Enerji (Nm) & Çöküntü Miktarı (mm) & Değerlendirme \\
\hline 1 & 359 & 516,56 & 5,00 & Delinme Yok \\
\hline 2 & 359 & 516,56 & 5,00 & Delinme Yok \\
\hline 3 & 388 & 601,26 & 5,50 & Delinme Yok \\
\hline 4 & 428 & 733,57 & 6,30 & Delinme Yok \\
\hline Ortalama & 384 & 591,99 & 5,49 & \\
\hline
\end{tabular}

B1 adlı numunede ortalama atış hızı değeri 369 m/sn' dir. Elde edilen ortalama çöküntü değeri 5,53 mm' dir. Bu numune NIJ Seviye II-A standardına göre koruma sağlamaktadır. B1 numunesine yapılan atışlar sonucunda atış hızına göre çöküntü miktarı grafiği Şekil 10 da verilmiştir.

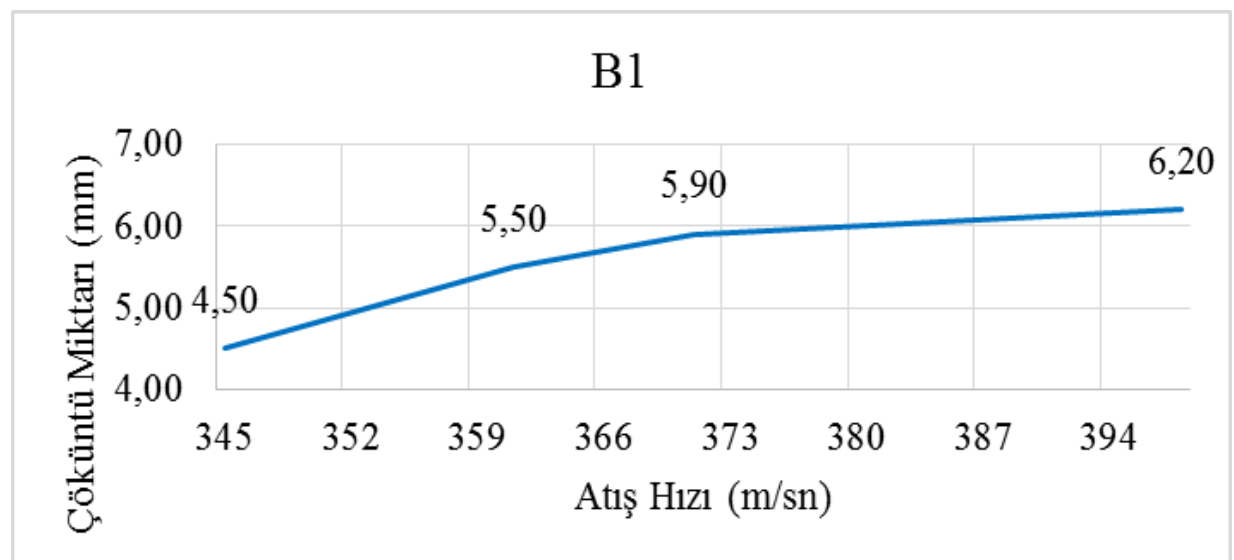

Şekil 10. B1 numunesine ait atış hızı-çöküntü miktarı grafiği

B2 adlı numunede ortalama atış hızı değeri 367 m/sn' dir. Elde edilen ortalama çöküntü değeri 6,71 mm' dir. Bu numune NIJ Seviye II-A standardına göre koruma sağlamaktadır. B2 numunesine yapılan atışlar sonucunda atış hızına göre çöküntü miktarı grafiği Şekil 11' de verilmiştir. 


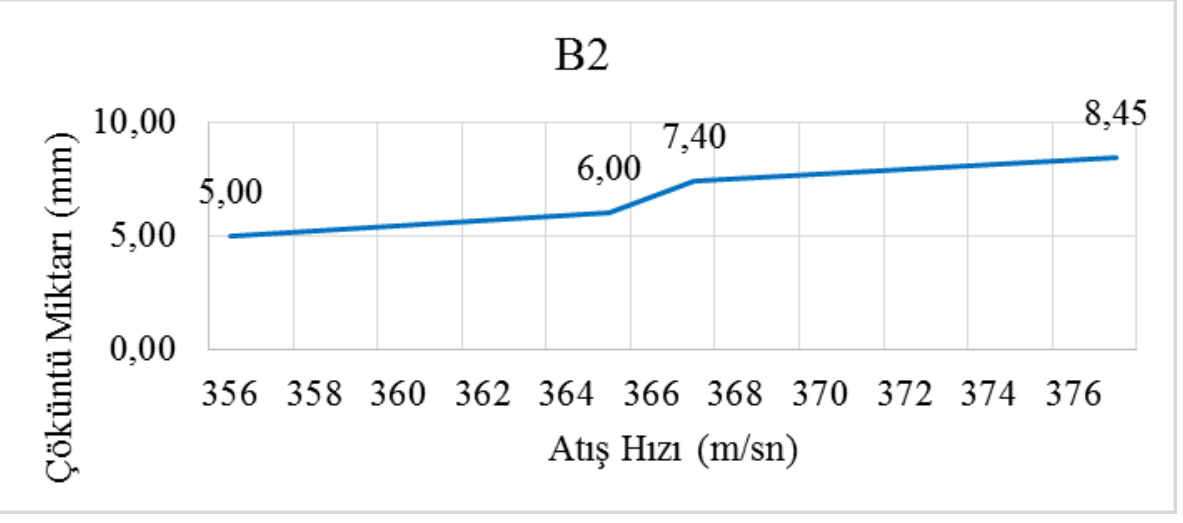

Şekil 11. B2 numunesine ait atış hızı-çöküntü miktarı grafiği

B3 adlı numunede ortalama atış hızı değeri $381 \mathrm{~m} / \mathrm{sn}$ ' dir. Elde edilen ortalama çöküntü değeri 7,93 mm' dir. Bu numune NIJ Seviye II-A standardına göre koruma sağlamaktadır. B3 numunesine yapılan atışlar sonucunda atış hızına göre çöküntü miktarı grafiği Şekil 12' de verilmiştir.

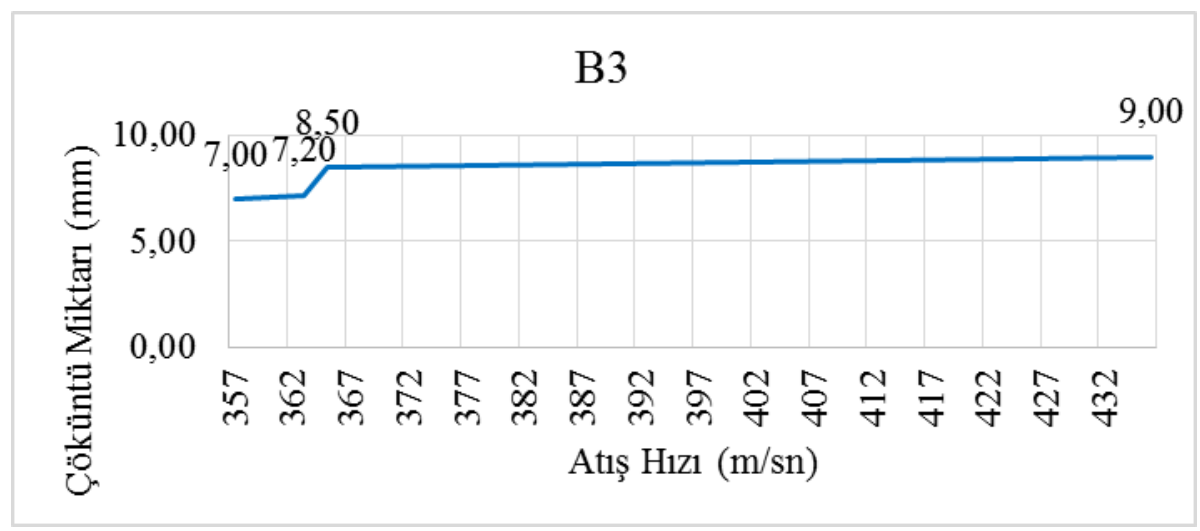

Şekil 12. B3 numunesine ait atış hızı-çöküntü miktarı

B4 adlı numunede ortalama atış hızı değeri 384 m/sn' dir. Elde edilen ortalama çöküntü değeri 5,49 mm' dir. Bu numune NIJ Seviye II-A standardına göre koruma sağlamaktadır. B4 numunesine yapılan atışlar sonucunda atış hızına göre çöküntü miktarı grafiği Şekil 13' de verilmiştir.

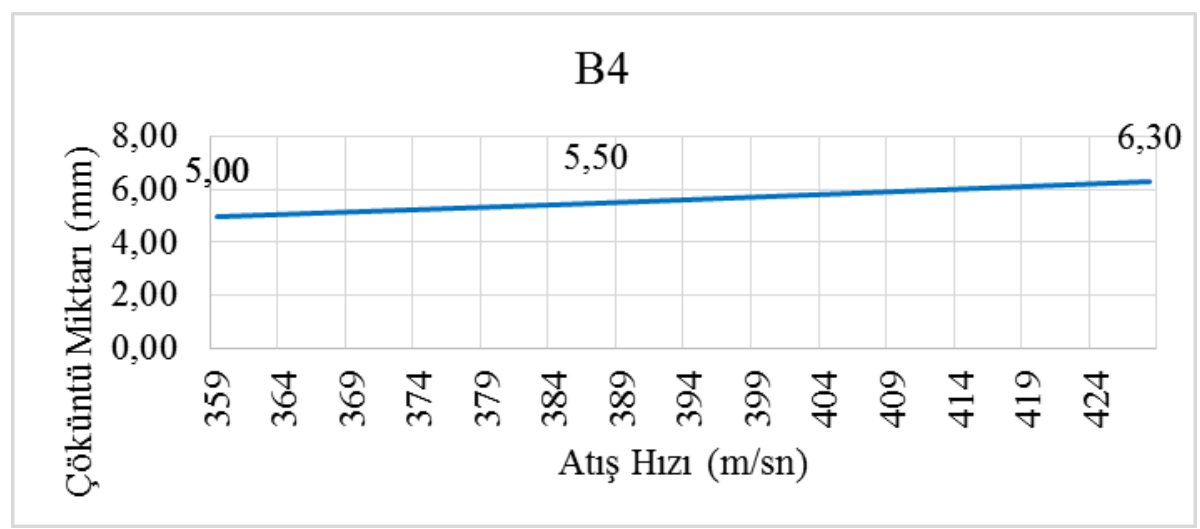

Şekil 13. B4 numunesine ait atış hızı-çöküntü miktarı grafiği

Dört numune arasında kalınlık, ağırlık ve çöküntü miktarı göz önüne alınarak yapılan karşılaştırmada B4 adlı numune 5.45 ortalama çöküntü miktarı ile en başarılı numune olmuştur. Bu dört numune arasındaki karşılaştırma Şekil 14 ve Şekil 15' de verilmiştir. 


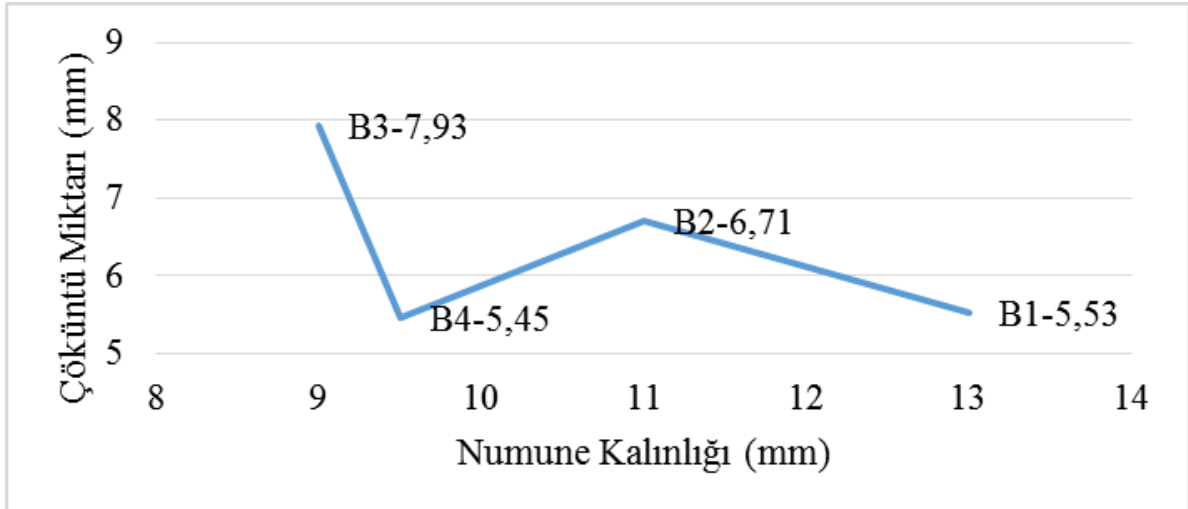

Şekil 14. Numunelerin kalınlık-çöküntü miktarı olarak karşılaştırılması

$13 \mathrm{~mm}$ ile en kalın numune olan B1 adlı numune 5,53 $\mathrm{mm}$ çöküntü miktarına sahiptir. $11 \mathrm{~mm}$ kalınlığa sahip olan B2 adlı numunenin çöküntü miktarı 6,71 mm'dir. B3 adlı numune 9 mm ile en ince numunedir ve çöküntü miktarı 7,93 mm'dir. 9,5 mm kalınlığı olan B4 adlı numune 5,45 mm çöküntü miktarı ile en başarılı numune olmuştur.

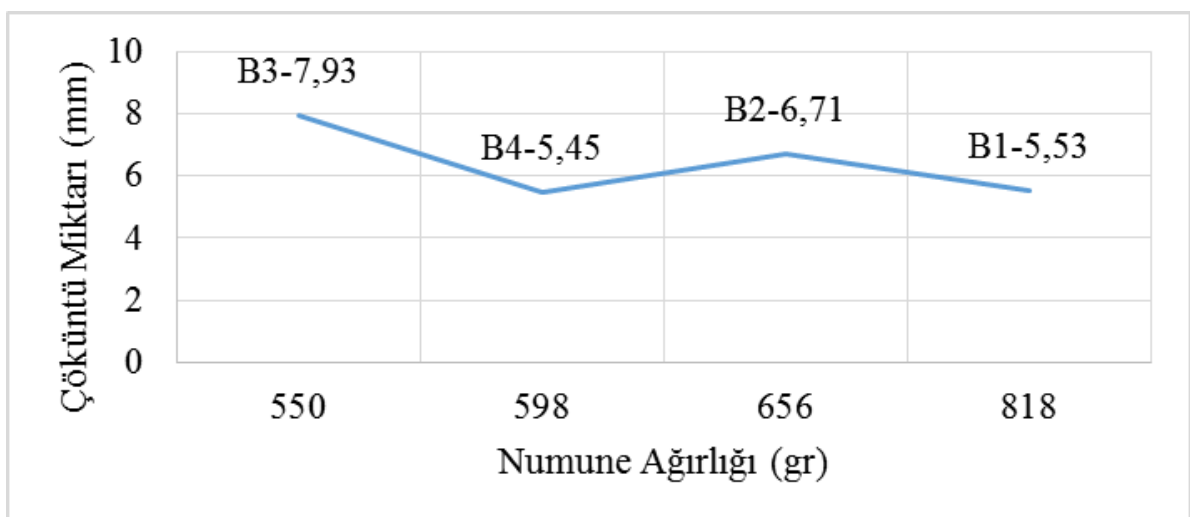

Şekil 15. Numunelerin ağırlık-çöküntü miktarı olarak karşılaştırılması

B1 adlı numune 818 gr ile en ağır numunedir ve çöküntü miktarı 5,53 mm'dir. 656 gr ağırlığı olan B2 adlı numunenin çöküntü miktarı 6,71 mm'dir. En hafif numune olan B3 adlı numunenin ağırlığ1 550 gr'dır ve $7,93 \mathrm{~mm}$ çöküntü miktarı ile dört numune arasında çöküntü miktarı en fazla olan numunedir. B4 adlı numune 5,45 mm çöküntü miktarı ile en başarılı olan numunedir ve ağırlığı 598 gr'dir.

\section{Sonuçlar}

Bu çalışmada tabakalı hibrit kompozitlerin bireysel zırh malzemesi olarak kullanılabilirliği deneysel olarak araştırılmıştır.

Çalışmanın ilk bölümünde 4 adet 30 katlı tabakalı hibrit kompozit plaka üretilmiştir. Daha sonra bu plakalara NIJ standartlarına uygun olarak $5 \mathrm{~m}$ mesafeden mermi hızları ölçülerek ve $9 \mathrm{~mm}$ FMJ mermiler kullanılarak atış testleri yapılmış ve sonuçları incelenmiştir.

B1 adlı numuneye yapılan tüm atışlar plaka içerisinde tutularak balistik testler başarı ile sonuçlanmıştır. En arkada sert yapısıyla destek plakası görevi gören karbon fiber kumaşta, merminin uyguladığı kuvvetle karbon fiber kumaşın $45^{\circ}$ olması sebebiyle $\pm 45^{\circ}$ yönünde fiber hasarı meydana gelmiştir. 
B2 adlı numuneye yapılan tüm atışlar plaka içerisinde tutularak balistik testler başarı ile sonuçlanmıştır. En arkada olan ve destek plakası görevi yapan karbon fiber kumaşın $0^{\circ}$ olması sebebiyle merminin etkisiyle karbon fiber üzerinde yatay fiber hasarı meydana gelmiştir.

B3 adlı numuneye yapılan tüm atışlar plaka içerisinde tutularak balistik testler başarı ile sonuçlanmıştır. En arkada olan karbon fiber kumaşın plain olması sebebiyle hem yatay hem dikey yönde fiber hasarı meydana gelmiştir.

B4 adlı numuneye yapılan tüm atışlar plaka içerisinde tutularak balistik testler başarı ile sonuçlanmıştır. En arkada destek plakası olarak çalışan karbon fiber kumaşta herhangi bir hasar meydana gelmemiştir.

Sonuçlar değerlendirildiğinde balistik testlerde en başarılı olan numunenin en ağır ve en kalın numune olan B1 adl $\left[\mathrm{Cam}\left(45^{\circ}\right)_{10} / \operatorname{Aramid}(\operatorname{Plain})_{10} / \operatorname{Karbon}\left(45^{\circ}\right)_{10}\right]$ dizilimine sahip numunesinin değil, [Cam(Twill) ${ }_{10} /$ Aramid(Plain) $\left.{ }_{10} / \operatorname{Karbon}\left(T_{w i l l}\right)_{10}\right]$ dizilimli olan B4 adlı numunesi olduğu tespit edilmiştir. $\mathrm{Bu}$ sonuçlar neticesinde twill dokuma yapısına sahip kumaşların balistik dayanımının daha iyi olduğu ortaya çıkmıştır.

Zırh malzemelerin tasarımında koruma kadar önemli bir diğer faktörde hafifliktir. Bu çalışma kapsamında yapılan balistik deneylerde başarılı olan numunelerin kat adedi düşürülerek çalışmaya devam edilebilir.

\section{Kaynaklar}

[1] Yavaş, M.O., (2009). Hafif Silahlara Karşı Bireysel Savunma Amaçlı Kompozit Malzeme Tasarımı ve Balistik Dayanımı, Yüksek Lisans Tezi, Selçuk Üniversitesi, Fen Bilimleri Enstitüsü

[2] Lane, R. A., (2005). High Performance Fiber for Personel and Vehicle Armor Systems, Amptiac, USA.

[3] Tan V. B. C., Lim C, T., Cheong C.H., "Perforation of high-strength fabric by projectiles of different geometry", International Journal of Impact Engineering, 2003, 28(2): 207-222.

[4] Karahan, M., Kuş, A., Eren R., 2007. An investigation into ballistic performance and energy absorption capabilities of woven aramid fabrics. Elsevier International Journal of Impact Engineering, 35, 499-510.

[5] Bilişik, A.K., Turhan, Y., 2009. Multidirectional stitched layered aramid woven fabric structures and their experimental characterization of ballistic performance. Textile Research Journal, 79, 1331-1343.

[6] Yu Y.M., Wang X.J., Lim C.W., 2009. Ballistic impact of 3D orthogonal woven composite by a spherical bullet: experimental study and numerical simulation. International Journal of Enginnering and Applied Sciences, 1, 1-18.

[7] NIJ Standard-0101.06 BallisticResistance of Body Armor

[8] Candan, C., Akdemir, A., 2004. An investigation of terminal ballistic properties and design of composite armor against the light weapons, 10. Denizli Malzeme Sempozyumu ve Sergisi, 147 154.

[9] Yılmaz, H., 2012. Üç Fazlı Tabakalı Karma Kompozit Yapının Balistik Özelliklerinin İncelenmesi, Doktora Tezi, Süleyman Demirel Üniversitesi, Fen Bilimleri Enstitüsü, Isparta.

[10] Wilhelm, M., Bir, C., Injuries tolawen forcement officers: the back face signature injury, Forensic SciInt., 2007, Vol. 174(1), 6-11. 